\title{
Electrochemical and others techniques for the determination of malic acid and tartaric acid in must and wine
}

\author{
Lenka Sochorova, Lucie Torokova, Mojmir Baron, Jiri Sochor* \\ Department of viticulture and enology, Faculty of Horticulture, Mendel University in Brno, Valtická \\ 337, CZ-691 44 Lednice, Czech Republic \\ *E-mail: jiri.sochor@mendelu.cz
}

doi: $10.20964 / 2018.09 .20$

Received: 8 May 2018 / Accepted: 25 May 2018 / Published: 5 August 2018

\begin{abstract}
This work is focused on a clear summary of the analytical techniques used for qualitative and quantitative analysis of malic acid and tartaric acid in wine and must. Particular emphasis is placed on electrochemical methods. The methods applied are divided into 5 basic groups — chromatographic, electrochemical, spectroscopic, enzymatic and titration. Some of these methods are already receding or are used only to a limited extent, mostly by small-scale winegrowers. The most widespread method in this field is high performance liquid chromatography combined with various types of detectors. The methods of capillary electrophoresis are on the rise. Expansion of spectroscopic and enzymatic techniques is not very significant and is mainly used in combination with other techniques.

With the constant development of instrumentation, the analysis of these basic acids has become very accurate and the analysis time has been minimized. Currently is experimentally tested a combination of these techniques to bring financial savings into sample analysis.
\end{abstract}

Keywords: malic acid, tartaric acid, chromatography technique, electrochemistry, spectroscopy, enzymatic and titration technique

\section{FULL TEXT}

(C) 2018 The Authors. Published by ESG (www.electrochemsci.org). This article is an open access article distributed under the terms and conditions of the Creative Commons Attribution license (http://creativecommons.org/licenses/by/4.0/). 